\title{
Fabrication and Characterization of Nanostructured Polymer Composites Prepared by Melt Compounding
}

\author{
Abdolmajid Alipour
}

\begin{abstract}
In this research we have investigated the effect of different percentages of nanoclay and matrix compositions on the characteristics of NR/BR blend prepared by open two-roll mill. The dispersion of the layered silicate in rubber matrix was characterized by X-ray diffraction (XRD) The results showed that the nanocomposites structure consisting of intercalated structure as well as partially exfoliated structure are obtained. Properties such as permeability and complex viscosity as well as storage modulus are tested to assess the effect of addition of the nanoclay and matrix composition. Permeability and compression set of the nanocomposite samples received markedly improvement. These results were confirmed by Gel content measurements since a noticeable decrease in the gel values was observed when the organoclay was added to the rubber compounds. The properties improvement caused by nanoclay are attributed to intercalation of the organophilic clay by NR/BR macromolecules and established interaction between nanoclay and polymer matrix which was evidenced by SEM photomicrographs. These results were accompanied by enhanced rheological properties.
\end{abstract}

Index Terms-Nanoclay, nanocomposite, $x$-ray diffraction, SEM photomicrographs, rheological properties

\section{INTRODUCTION}

Polymer blends have been intensively studied because of their theoretical and practical importance. Among the blends widely investigated in rubber industries are natural rubber (NR)/styrene-butadiene rubber (SBR), NR/butadiene rubber (BR), and NR/ BR/SBR.

Synthetic rubbers are classified into general purpose rubbers and special purpose rubbers. Polybutadiene is classified as general purpose rubbers intended for the manufacture of tires and general mechanical products. However, one type of rubber may not possess all the physical properties desired in a finished product. Much attention is currently being devoted to the simplest route for combining the outstanding properties of different existing polymers, i.e., the formation of polymer blends [1]. For example, in tread compounds, the high abrasion resistance under certain conditions conferred by the use of BR is desirable, but the poor road holding and rib tearing properties are not, hence blends of BR with NR and styrene-butadiene rubber are employed. Compatibility is the fundamental property, deciding the practical utility of a polymer blend.

If the two elastomers in a blend are incompatible, it will

Manuscript received January 1, 2012; revised February 22, 2012. This work was supported in part by the Islamic Azad University, Zarghan Branch

Abdolmajiid Alipour is with the Young Researchers Club, Zarghan Branch, Islamic Azad University, Zarghan, Iran (phone: +989123399823; fax: +987124226911; e-mail: Abdolmajid.Alipoor@gmail.com). exist in the form of two separate phases and the cured blend will showinferior properties. In NR/BR blends, BR shows improved tread wear and groove cracking resistance without reduction in resilience. The most important advantage of adding BR to NR is the improved abrasion resistance.

The reinforcement of rubbers is expressed by enhancement of the modulus, failure properties (tensile and tear strength), and abrasion resistance of the vulcanizates. The main aim for filler addition is to improve certain properties and cheapen the compound. In the last two decades, research was focused on the development of other reinforcing agents to replace carbon black in rubber compounds. The synthesis of inorganic-organic complex materials has been widely done for the purpose of preparing noble materials with various special properties. Nanocomposites are composites in which an inorganic filler is dispersed within a polymer matrix at a nanoscale level, thus the clay layer could be intercalated or exfoliated into the polymer to form clay/polymer nanocomposites. In other words, the polymer is nanoscopically confined. Nanocomposites exhibit greatly improved mechanical and thermal properties because of the nanometre-scale dispersion of the reinforcements and the high surface-to volume ratio [2]. Clay silicates, such as montmorillonite, hectorite, bentonite, etc, have been used as reinforcing fillers for polymers because of their potentially high aspect ratios [3], [4], [5]. The crystal structures of clays are usually interesting in their own right. Their crystal lattice consists of two-dimensional layers where a central octahedral sheet of either aluminum or magnesium is fused to two external silica tetrahedra by their tip so that the oxygen ions of the octahedral sheet also belong to the tetrahedral sheets. The layer thickness is around $1 \mathrm{~nm}$ and the lateral dimensions of these layers may vary from $300^{\circ} \mathrm{A}$ to several microns and even larger, depending on the particular silicate. The layers are stacked by a weak dipole force and exhibit a net negative charge on the lamellar surface; the interlayers between the galleries are normally occupied by cations such as $\mathrm{Na}+$ and $\mathrm{Ca}++$. As the forces that hold the stacks together are relatively weak, the intercalation of small molecules between the layers is easy. The metal cations of the interlayer can be exchanged with organic quaternary alkylammonium salts with long chains, thus producing organophilic clays, also called organoclays, to give surfaces that are less ionic or polar. Organophilic modification improves the compatibilization between the surface of the clay and the hydrophobic polymer matrix and thus the polymers penetrate more easily into the galleries. These entering guest molecules can either simply increase the distances between the still-parallel layers in an intercalation process or randomly disperse the separate sheets entirely in an exfoliation process. 
For true nanocomposites, the clay nanolayers must be uniformly dispersed (exfoliated) in the polymer matrix, as opposed to being aggregated as tactoids or simply intercalated. When nanolayers have been exfoliated, the improvement in properties can be seen as an increase in tensile properties, as well as enhanced barrier properties, decreased solvent permeability, and increased thermal stability and flame retardance. [6], [7].

In recent years, Polymer/clay nanocomposites (PCNs), emerged as a new class of material, have attracted negligible interest from academia and industry [2] - [15]. Compared with their relative micro and macro scale counterparts and their pristine polymer matrices, PCNs exhibit significantly improved performances such as tensile strength, modulus, heat resistance, gas barrier, swelling resistance, etc. Nanoclay is a hydrophile mineral which would not have an appropriate compatibility and adhesion to non-polar polymers. This problem could be solved by modification of clay using alkyl ammonium or alkyl phosphonium cations. Substitution of hydrated metallic ions by organic cations has an important role in balancing the negative ions and modification of clay from hydrophile to hyrophobe. Such a modification on the clay causes the surface energy to get defaced and the nano-filler will be compatible with organic polymers. It seems that the interaction between adjacent silicate layers having negative charge has the main role in the possibility of positive organic ions to enter the galleries. As the modified clay is dispersed in the polymeric matrix, ammonium ions and polymer chains attract each other. On the other hand the repulsion between clay layers facilitates the entrance of polymer chains into the galleries of silicate Very recently, increasing attention has been paid on rubber/clay nanocomposites (RCNs). According to reports, Several RCNs based on one or two elastomers has been prepared via solution intercalation, melt intercalation, and rubber-latex compounding [6] - [15]. But to our knowledge, no studies have been published on NR/BR nanocomposites prepared by melt intercalation in the literature.

\section{EXPERIMENTAL}

\section{A. Materials}

NR (SMR 20), Mooney Viscosity ML $(1+4)$ at $100{ }^{\circ} \mathrm{C}, 55$, BR (97\% 1, 4(cis)), Mooney Viscosity ML (1+4) at $100{ }^{\circ} \mathrm{C}$, 58 , nanoclay were supplied by Malaysia, China and Southern clay Ltd respectively. Compounding ingredients (zinc oxide (3.0), stearic acid (2.5), aminox (2.0), PVI, n-cyclohexylthiophthalimide (2.0), sulfur (2.5), TBBS, t-butyl-2-benzothiazolsulfenamide (0.6). The nanoclay used was Cloisite $15 \mathrm{~A}$ which was a natural montmorillonite modified with a dimethyl dehydrogenated tallow quaternary ammonium having a cation exchange capacity of 125 mequiv/100 g.ing ingeredients .

\section{B. Samples Preparation}

Nanocomposite samples were prepared by a laboratory open two-roll mill (Polymix 200-L) for $18 \mathrm{~min}$ at room temperature at the rotor speed of $80 \mathrm{rpm}$. It should be mentioned that firs nanoclay was pre-dried at temperature of $80^{\circ} \mathrm{C}$ for $24 \mathrm{hr}$, then NR and BR were blended and nanoclay and curing agents were added to the compound.

TABLE I: COMPOSITION (WT \%) AND NOMENCLATURE OF THE NANOCOMPOSITE SAMPLES PREPARED

\begin{tabular}{cccc}
\hline Sample & NR & BR & Nanoclay \\
\hline $\mathrm{S}_{1}$ & 75 & 25 & 0 \\
$\mathrm{~S}_{2}$ & 75 & 25 & 1 \\
$\mathrm{~S}_{3}$ & 75 & 25 & 3 \\
$\mathrm{~S}_{4}$ & 75 & 25 & 5 \\
$\mathrm{~S}_{5}$ & 75 & 25 & 7 \\
$\mathrm{~S}_{6}$ & 100 & 0 & 5 \\
$\mathrm{~S}_{7}$ & 50 & 50 & 5 \\
$\mathrm{~S}_{8}$ & 25 & 75 & 5 \\
$\mathrm{~S}_{9}$ & 0 & 100 & 5 \\
\hline
\end{tabular}

\section{Characterization}

Curing process were carried out on the Diffenbecher hot press at $160^{\circ} \mathrm{C}$ and 150 bar. To measure the change of gallery distance of organo- MMT before and after intercalation, $\mathrm{X}$-ray diffraction (XRD) was performed at room temperature with a Philips X-ray diffractometer model X'Pert. The X-ray beam was a $\mathrm{Cu} \mathrm{K} \alpha$ radiation $(\lambda=1.540598 \AA$ ) using a $50 \mathrm{KV}$ voltage generator and a $40 \mathrm{~mA}$ current. The rheological measurements of prepared samples were carried out using RPA oscillatory rheometer at temperature of $80{ }^{\circ} \mathrm{C}$ and frequency of $0.01-80 \mathrm{~Hz}$. In order to study the morphological properties, SEM micrographs of cryogenically fractured surface of gold coated samples were taken with a TESCAN electron microscope. The permeation experiment of nitrogen was carried out with gas permeability-measuring apparatus. The pressure on one face of the sheet (about $1 \mathrm{~mm}$ in thickness and $8 \mathrm{~cm}$ in diameter) was kept at $0.57 \mathrm{MPa}$ and the other face at zero pressure, and nitrogen permeated through the sheet. The rate of transmission of nitrogen at $40{ }^{\circ} \mathrm{C}$ was obtained by gas chromatography and the nitrogen permeability was calculated from it. Gel content values were calculated according to the weight loss of the sample washed with acetone after a 24 hrs dipping in boiling toluene. Compression set testing measures the ability of the rubber to return to its original thickness after prolonged compressive stresses at a given temperature and deflection. As a rubber material is compressed over time, it loses its ability to return to its original thickness. This loss of resiliency may reduce the capability of a rubber seal to perform over a long period of time. The resulting permanent set that a seal may take over time may cause a leak. Compression Set results for a material are expressed as percentage. The lower the percentage figure, the better the material resists permanent deformation under a given deflection and temperature range. The specimens are compressed by $50 \%$ at $100^{\circ} \mathrm{C}$ for $24 \mathrm{hr}$.

\section{RESULTS AND DISCUSSION}

\section{A. X-ray Diffraction}

$\mathrm{XRD}$ is a powerful technique to follow the intercalation of polymer chains into the silicate layers of clay and dispersion 
of organoclay in the polymer matrix. XRD patterns of the NR75/BR25 samples containing 1, 3, 5 and $7 \mathrm{wt} \%$ is typically shown in Fig 1. As we know, the organoclay (Closite 15A) presents a peak at $2 \theta=2.9$, which as deduced by the Bragg equation corresponds to an interlayer distance of $31.5 \AA$. Shift of the organoclay diffraction peak to lower $2 \theta$ values indicated that elastomer chains intercalated between consequent silicate layers. This clearly indicates that inter lamellar spacing of the clay are enlarged after melt compounding [2].

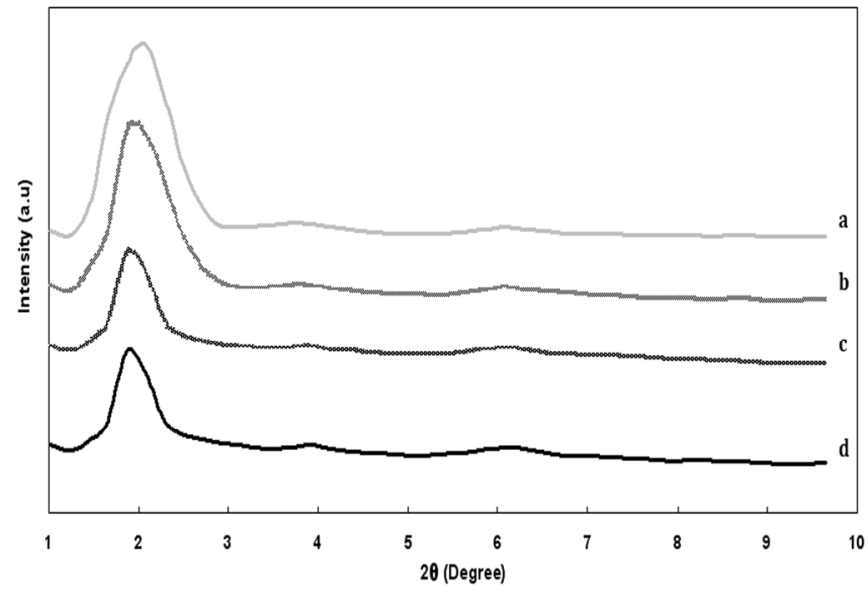

Fig. 1. XRD results of NR/BR (75/25) containing a) 7 b) 5

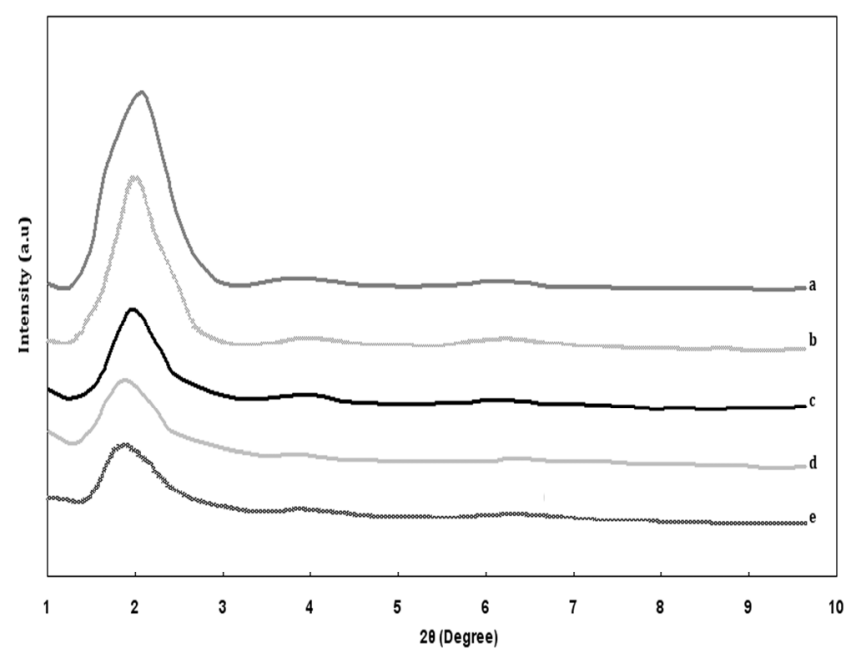

c) 3 d) $1 \mathrm{Wt} \%$ nanoclay

Fig. 2. XRD results of NR/BR blends a) $100 / 0$ b) $75 / 25$ c) $50 / 50$ d) $25 / 75$ e) $0 / 100$ containing $5 \mathrm{Wt} \%$ nanoclay

Moreover, XRD results of different compositions of $\mathrm{NR} / \mathrm{BR}$ containing $5 \mathrm{wt} \%$ is shown in Fig 2 . As can been seen, as the BR content of the samples increases, the organoclay diffraction peak shifts toward lower angles and consequently, the peak intensity declines. It can be attributed to the higher Mooney viscosity of BR resulting in a higher shear stress undergone by the matrix. This might help the deagglomeration of the clay stocks within the matrix [2].

\section{B. SEM Results}

Further insights on the morphology of these materials are found in Fig. 6, where SEM images of cryogenically fractured and nanocomposite samples based on NR/BR $(75 / 25)$ with and without clay are reported. As seen the fractured surface of pristine NR/BR (Fig 3-a) is smooth. The harsh surface of NR/BR filled compound by $7 \mathrm{wt} \%$ nanoclay (Fig 3-b) exemplifies an effective interaction established between polymer matrix / filler [2], [15]. The SEM photomicrographs shown in Figure 6 confirm that smaller particle size of the filler provides a larger surface area for a better filler dispersion and interfacial bond between filler and rubber matrix.
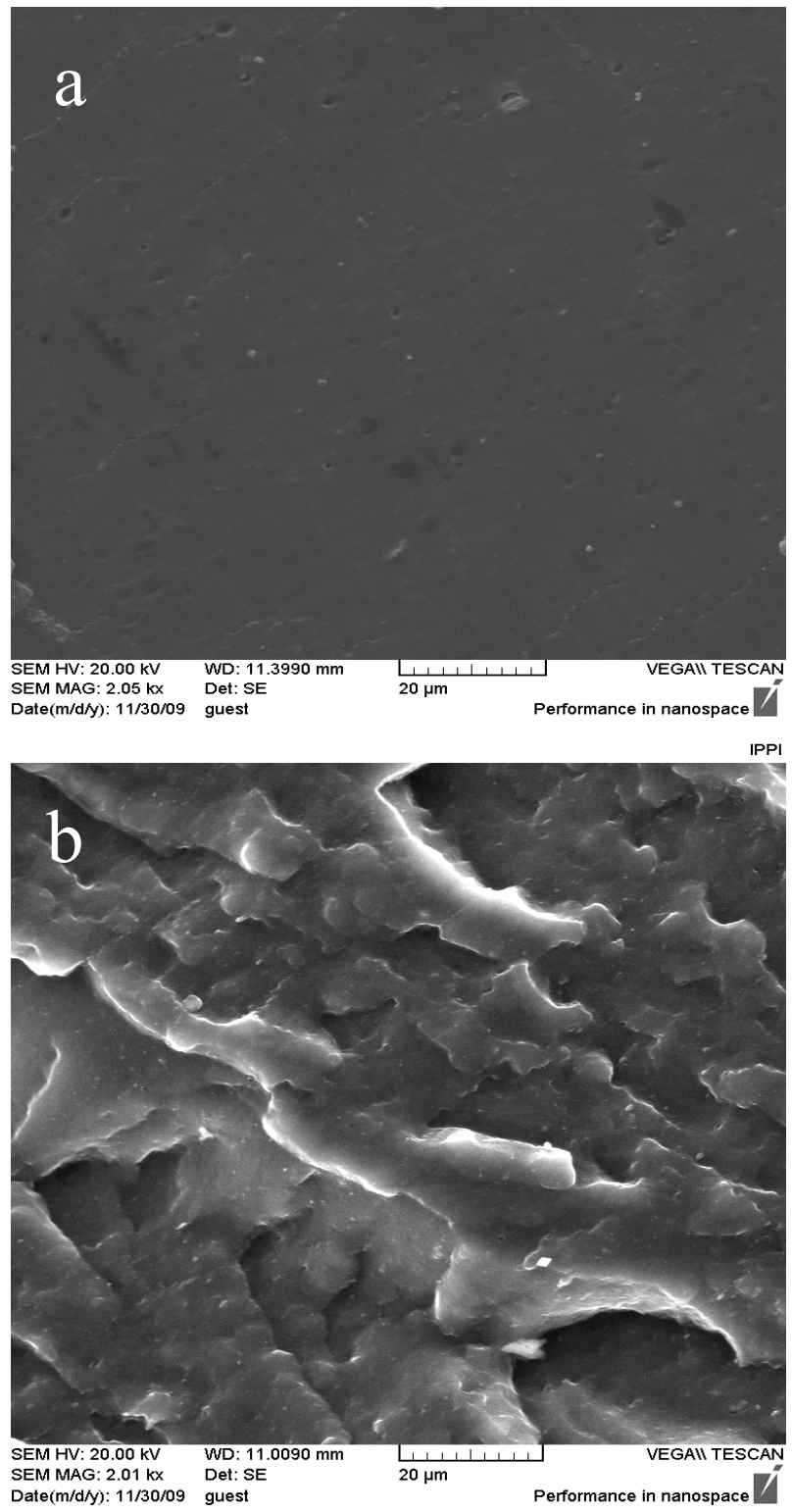

IPPI

Fig. 3. SEM photomicrographs of NR75/BR/ 25 containing a) no nanoclay $b$ ) $5 \mathrm{Wt} \%$ nanoclay

\section{Permeability}

The gas permeability of gum NR/BR vulcanizate and $\mathrm{NR} / \mathrm{BR} /$ clay nanocomposites is presented in Table 2. As shown in Table 2, the nitrogen permeability reduces with an increased amount of clay. Compared with the gum NR/BR vulcanizate, the nitrogen permeability of $\mathrm{NR} / \mathrm{BR} /$ clay nanocomposites with $1,3,5$, and $7 \mathrm{Wt} \%$ clay reduces by $10.675,9.651,8.340$ and 7.752 respectively. It can be concluded that the clay layers with the large aspect ratio and the planar orientation lead to the great increase of the diffusion distance by creating a tortuous path for the diffusing gas. 
TABLE II: NITROGEN PERMEABILITY OF NR/BR/CLAY NANOCOMPOSITES $\left(10^{-17} \mathrm{M}^{2} \mathrm{PA}^{-1} \mathrm{SEC}^{-1}\right)$

\begin{tabular}{c|ccccc}
\hline & & & & & \\
$\begin{array}{c}\text { Material } \\
\text { (NR/BR/Nanoclay) }\end{array}$ & $75 / 25 / 0$ & $75 / 25 / 1$ & $75 / 25 / 3$ & $75 / 25 / 5$ & $75 / 25 / 7$ \\
\hline & & & & & \\
\hline & & & & & \\
Permeability & 12.1 & 10.675 & 9.651 & 8.340 & 7.752 \\
& & & & & \\
\hline
\end{tabular}

\section{Gel Content}

Table 3 illustrates the gel content variation of NR/BR (75/25) nanocomposite samples containing $0,3,5,7$ and 10 $\mathrm{wt} \%$ Nanoclay. As expected, addition of nanoclay particles results in an increase in the crosslink density of the samples and consequently a decrease in the gel content values. Similar trends were observed and reported by other researchers [2].

TABLE III: GEL CONTENT VALUES FOR NR/BR SAMPLES CONTAINING DIFFERENT PERCENTAGES OF NANOCLAY

\begin{tabular}{c|ccccc}
\hline & & & & & \\
$\begin{array}{c}\text { Material } \\
\text { (NR/BR/Nanoclay) }\end{array}$ & $75 / 25 / 0$ & $75 / 25 / 1$ & $75 / 25 / 3$ & $75 / 25 / 5$ & $75 / 25 / 7$ \\
\hline & & & & & \\
\hline & & & & & \\
Gel Content(\%) & 91 & 87.50 & 84.651 & 81.40 & 80.02 \\
& & & & & \\
\hline
\end{tabular}

\section{E. Rheological Properties}

Rheological properties of nanocomposite materials is a great of interest and has been investigated by several researchers [2], [6], [8], [9]. The complex viscosity $\left(\eta^{*}\right)$ and elastic modulus $\left(G^{\prime}\right)$ of prepared samples are shown in Fig 4. As seen, complex viscosity of prepared samples in sensibly higher than that of pure NR/BR. It can be attributed to the established interaction between polymer/filler. The falling trend of viscosity with frequency represents the pseudoplastic nature and shear-thinig behaviour of samples. At low and medium range of frequencies, the complex viscosity showed an increase indicating a yield stress. The existence of yield stress, has been indicated as a common characteristic of highly filled polymer melts, associated with interaction between the filler particles [2], [14]. Elastic modulus also increases with clay loading which would be ascribed to the good interactions established between the matrix components and organoclay functional groups [2], [14].

\section{F. Compression Set}

Compression set testing measures the ability of the rubber to return to its original thickness after prolonged compressive stresses at a given temperature and deflection. As a rubber material is compressed over time, it loses its ability to return to its original thickness. This loss of resiliency may reduce the capability of a rubber seal to perform over a long period of time. The resulting permanent set that a seal may take over time may cause a leak. Compression Set results for a material are expressed as percentage. The lower the percentage figure, the better the material resists permanent deformation under a given deflection and temperature range. The results of the compression set for the samples of NR/BR/Nanoclay are shown in Fig. 5. Comparison of the samples results indicates that unfilled NR/BR reinforced by $7 \mathrm{Wt} \%$ nanoclay has the lowest percentage of compression, which means that it resists permanent deformation better than the other samples.

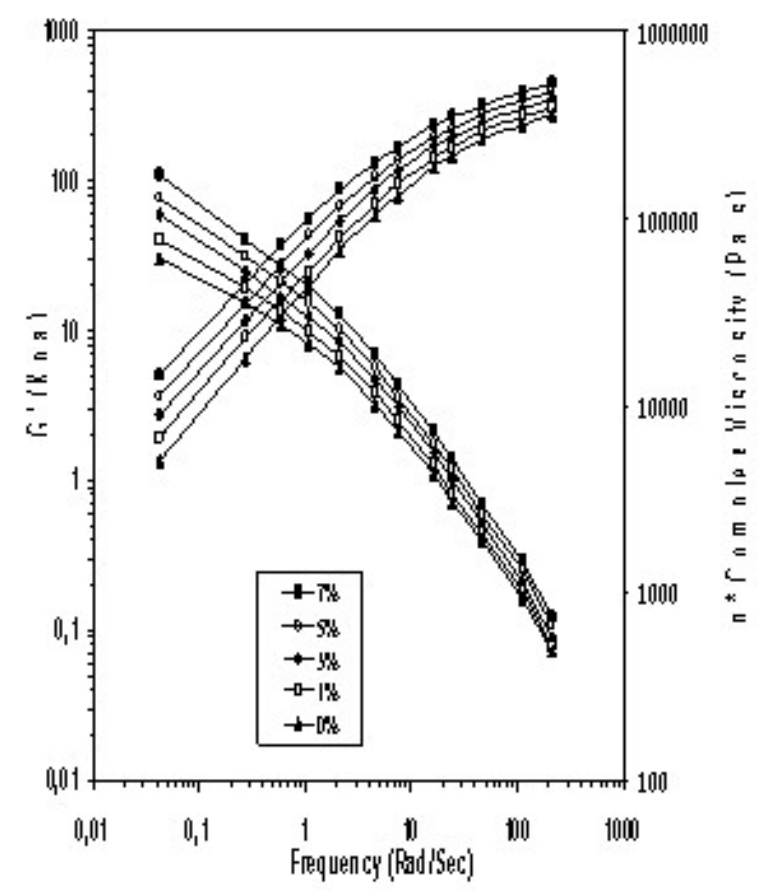

Fig. 4. Rheological properties of NR/BR (75/25) Nanocomposite samples

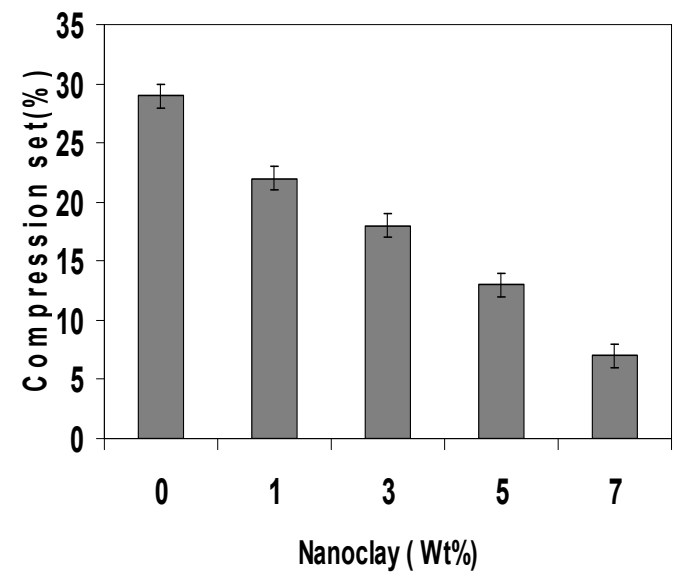

Fig. 5. Comression set results of NR 75/BR 25 reinforced by 1, 3, 5 and 7 wt $\%$ nanoclay

Compression set is a measure of the ability of the rubber to retain their elastic properties after prolonged compression at a constant strain under specific set of conditions, and its permanent set of rubber compounds. The poor performance of materials in terms of compression set is attributed to uncross-linked chains and to network defects such as long dangling chains, which do not contribute to the permanent network and are able to relax during the compression stage, 
then providing no elastic contribution to the recovery stage. in the case of NR/BR samples the nanoclay results in restriction in polymer chain movements and lower compression set. Alipour et al. [15] have reported that increased formation of effective network chains or crosslinking in the deformed state decreases compression set. It should be noted that the smaller the size of particles the lower the compression set could become. Therefore addition of nanoclay in the current study with resultant reduced compression set indicates such effects reported by previous researchers.

\section{G. Dynamic Properties}

To complete our exploration on the effects of nanoclay in a NR/BR rubber compound we looked also at certain dynamic properties such as the generation of heat under cyclic deformation. We have used the classic test of the Goodrich flexometer and the temperature increase was then divided by the hardness of the sample to have a heat index. The results of this observation for NR/BR (75/25) reinforced by 1, 3, 5 and $7 \mathrm{Wt} \%$ nanoclay is shown in Fig 6 and Fig 7. It can be observed that the heat build up decreases by adding the nanoclay. Thus, the nanoclay offers also the beneficial effect of being able to reduce the hysteresis of a rubber compound [15].

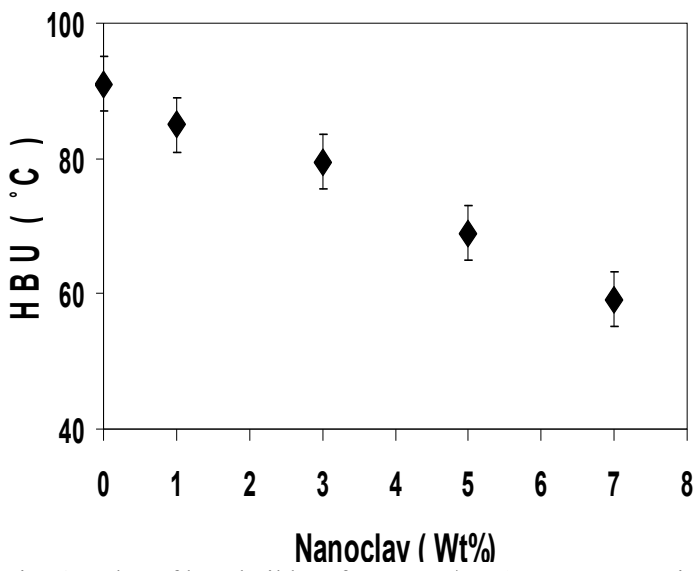

Fig. 6. Value of heat build up for NR 75/BR 25 nanocomposites

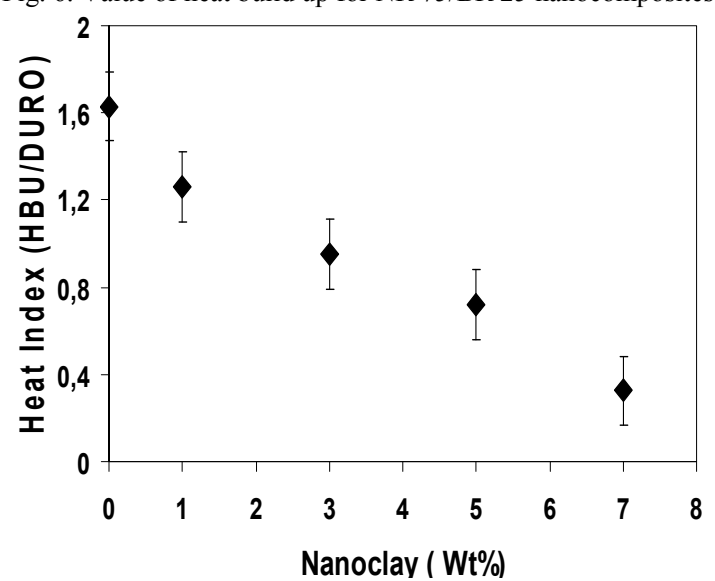

Fig. 7. Values of heat index for NR 25/BR 75 nanocomposite samples

\section{H. Interactions Between Layered Silicates and Rubber}

It was emphasized that better results were observed in organoclay partly due to better intercalation. From the results obtained, there were few possible ways that the clay could have interacted with the rubber matrix. Schematic diagrams are drawn in Fig 8 to illustrate the possible formation of composites from the interactions of layered silicates and rubber matrix. In the case of Fig 8-a, the rubber chains are not interacting with the silicates at all and a micro-rubber composite is formed. This is more like to occur when unmodified clay is used. In Fig 8-b, the rubber chains are partially intercalated into the galleries. Such 'partial' intercalation could be due to the following reasons:

- The viscosity of the rubber is too high and this restricts the movement of the molecular chains and prevents them from crawling into the silicate galleries.

- The vulcanization reaction is too fast and before the rubber chains can crawl into the galleries the movement is restricted by the formation of network. Thus, the intercalation only occurs at the entrance of the galleries.

- Since the method used for nanocomposite preparation is mechanical blending, the insufficient shear could cause the 'partial' intercalation.

Figure 8-c shows excellent interaction between the silicates and rubber as the rubber chains are completely intercalated between the silicate layers. From the interpretation of results, the type of rubber/clay nanocomposites obtained in our experiment is believed to be in between Figs 6-b and 6-c.
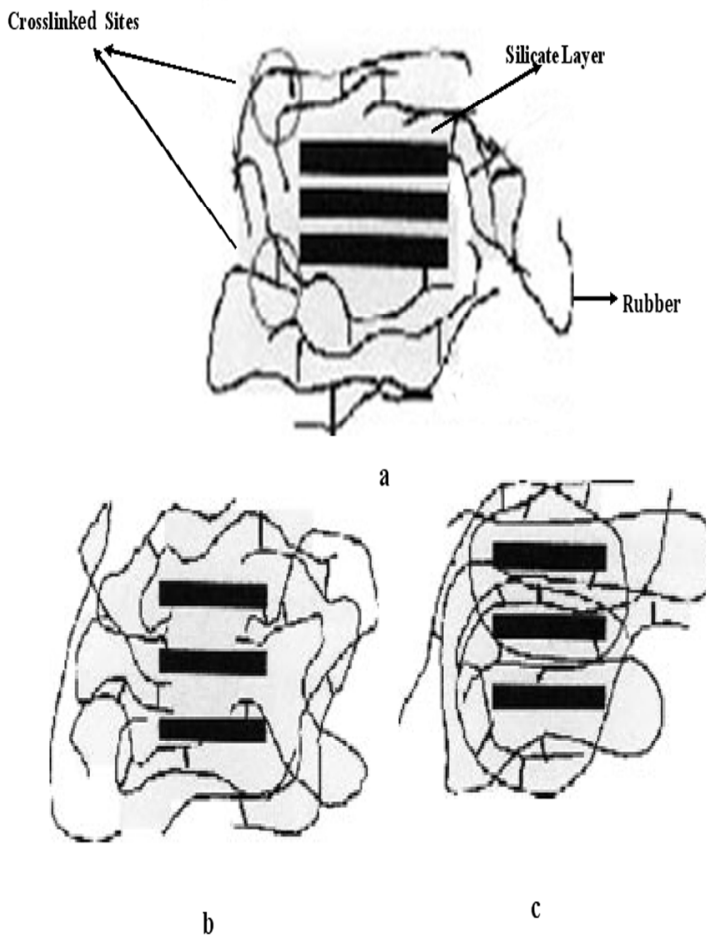

Fig. 8. Schematic diagram of the possible interactions between layered silicates and layers

\section{The Reinforcement of Layered Silicates in Rubber}

Reinforcement refers to the increase in stiffness and strength imparted to a vulcanizate by particulate filler.

It is dependent on the shape of hard domains and their interaction with the elastomeric matrix. However, the chemistry of elastomeric materials is very complex and they are capable of undergoing crosslinking to form a three-dimensional network when the right vulcanizing agent is added. The vulcanized or cured rubber is usually reinforced with fillers such as carbon black to enhance its properties and the reinforcement mechanism is known and rather straightforward to understand. However, the reinforcement of layered silicates is far more complicate 
owing to their unique structure and the interaction behaviour with the rubber matrix.

The rubber/clay nanocomposites in Fig 9-a would have superior mechanical properties as a constrained region is formed where the rubber chains have a restricted mobility. The failure is more likely to occur at the layered silicates (failure regions are circled). The properties of the rubber/clay nanocomposite in Fig 9-b depend greatly on the bonding between the layered silicate surface and rubber matrix and thus the failure is likely to occur at the interface of the silicates and the rubber matrix. The amount of layered silicates used and their homogeneity also have an influence on the reinforcement. Agglomeration tends to occur at higher loading of filler and results in the formation of weak spots. Thus, the composites would go through a maximum or critical filler loading before a drastic drop in properties is observed. The clay content used in the experiments was below the 'critical' amount as no dramatic drop was observed in the mechanical property results. Instead, the mechanical properties generally increased gradually as the clay content increased. Good dispersion of filler also plays an important role in composites. The mechanical properties which are obtained from an inhomogeneous composite are not the true properties. The reinforcement could be due to the original strength of the polymer matrix or the filler itself. Thus, good dispersion and distribution of the filler in the polymer matrix is critical.
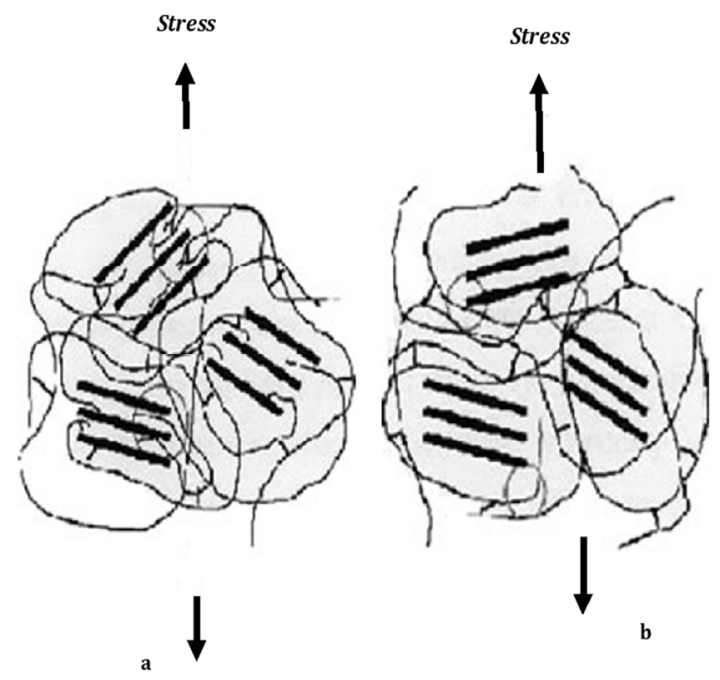

Fig. 9. Schematic diagram of the possible failure mechanism in nanocomposite samples

\section{CONCLUSION}

This work was devoted to investigate the rubber composition and nanoclay content on the properties of NR/BR/Closite 15A nanocomposites using different techniques. Experimental results of X-ray diffraction showed expansion of the distance between the silicate layers. Rheological properties, permeability and gel content values as well as compression set of the prepared samples received markedly improvement by clay loading. SEM photomicrographs showed that there is a strong interaction between polymer matrix and nanoclay particles in NR/BR filled samples compared to the pristine NR/BR.

\section{ACKNOWLEDGMENT}

The funding assistance by young researchers club, Zarghan branch, Islamic Azad University, Zarghan, Iran, is acknowledged by the author.

\section{REFERENCES}

[1] S. H. Botros, "Preparation and characteristics of NR/EPDM rubber blends," Polym Plast Technol Eng., vol 41, pp. 341-359, 2002.

[2] A. Alipour, G. Naderi, G. R. Bakhshandeh, H. Vali, and Sh. Shokoohi, "Elastomer nanocomposites based on NR/EPDM: Morphology and properties. International Polymer Processing,” vol XXVI, pp. 48-55, 2011.

[3] G. Naderi, P. G. Lafleur, and C. Dubois, "Microstructure-properties correlations in dynamically vulcanized nanocomposite thermoplastic elastomers based on PP/EPDM," Polymer Engineering and Science, vol 47, pp. 207-217, 2007.

[4] G. Naderi, P. G. Lafleur, and C. Dubois, "Dynamically Vulcanized Nanocomposite Thermoplastic Elastomers Based on EPDM/PP (Rheology and Morphology)", International Polymer Processing, vol 2, pp. 120-127, 2007.

[5] G. Naderi, P. G. Lafleur, and C. Dubois, "The influence of matrix viscosity and composition on the morphology, rheology, and mechanical properties of thermoplastic elastomer nanocomposites based on EPDM/PP", Polymer Composites, vol 29, pp. 1301-1309, 2008.

[6] M. A. Lopez-Manchado, B. Herrero, and M. Arroyo, "Organoclay-natural rubber nanocomposites synthesized by mechanical and solution mixing methods," Polym Int, vol 53, pp.1766-1772, 2004

[7] A. K. Ghosh, S. C. Debnath, N. Naskar, and D. K Basu. "NR-EPDM covulcanization: A novel approach," J Appl Polym Sci., vol 181: pp. 800-808, 2000.

[8] S. Varghese, K. G.Gatos, and A. A. Apostolov, "Morphology and mechanical prop- erties of layered silicate reinforced natural and polyurethane rubber," J. Appl. Polym. Sci., vol 92, pp. 54-551 2004.

[9] S. Varghese, J. Karger-Kocsis, and K. G.Gatos. "Melt compounded epxidized natural rubber /layered silicate nanocomposites: structure-properties relationship," Polymer, vol 44, pp. 3977-3983, 2003.

[10] S. Ranimol, A. Rosamma, C. Treesa, S. Varghese, J. Kuruvilla, and T. Sabu, "Rheological behavior of nanocomposites of natural rubber and carboxylated styrene butadiene rubber latices and their blends," Journal of Applied Polymer Science., vol 101, 2355-2362, 2006.

[11] Y. Wang, H.Z. Zhang, and Y. Wu, "Structure and properties of strain-induced crystallization rubber-clay nanocomposites by co-coagulating the rubber latex and clay aqueous suspension," $J$ Appl Polym Sci., vol 96, pp. 318-323, 2005.

[12] H. Zheng, Y. Zhang, Z. Peng, and Y. Zhang, "Influence of the clay modification and compatibilizer on the structure and mechanical properties of ethylene-propylene-diene rubber/montmorillonite composites," Polymer Testing; vol 23, pp. 217-223, 2004.

[13] P. Li, L. Yin, G. Song, J. Sun, L. Wang, and H. Wang, "High-performance EPDM/organoclay nanocomposites by melt extrusion," Applied Clay Science, vol 40, pp. 38-44, 2008.

[14] A. Alipour, G. Naderi, G. R. Bakhshandeh, and Sh. Shokoohi, "Microstructure and Rheological Properties of NR/EPDM Caly Nanocomposites; Effect of Composition," Iranian Rubber Magazine, vol 62, pp. 26-34, 2011.

[15] A. Alipour, G. Naderi, and M. H. R. Ghoreishy," Effect of Nanoclay Content and Matrix Composition on Properties and Stress-Strain Behaviour of NR/EPDM Nanocomposites," J Appl Polym Sci., submitted for publication 